\title{
Use of community-level data in the National Children's Study to establish the representativeness of segment selection in the Queens Vanguard Site
}

\author{
Andrew Rundle ${ }^{1 *}$, Virginia A Rauh², James Quinn ${ }^{3}$, Gina Lovasi ${ }^{1}$, Leonardo Trasande ${ }^{4}$,
}

Ezra Susser ${ }^{1}$ and Howard F Andrews ${ }^{5}$

\begin{abstract}
Background: The WHO Multiple Exposures Multiple Effects (MEME) framework identifies community contextual variables as central to the study of childhood health. Here we identify multiple domains of neighborhood context, and key variables describing the dimensions of these domains, for use in the National Children's Study (NCS) site in Queens. We test whether the neighborhoods selected for NCS recruitment, are representative of the whole of Queens County, and whether there is sufficient variability across neighborhoods for meaningful studies of contextual variables.

Methods: Nine domains (demographic, socioeconomic, households, birth rated, transit, playground/greenspace, safety and social disorder, land use, and pollution sources) and 53 indicator measures of the domains were identified. Geographic information systems were used to create community-level indicators for US Census tracts containing the 18 study neighborhoods in Queens selected for recruitment, using US Census, New York City Vital Statistics, and other sources of community-level information. Mean and inter-quartile range values for each indicator were compared for Tracts in recruitment and non-recruitment neighborhoods in Queens.
\end{abstract}

Results: Across the nine domains, except in a very few instances, the NCS segment-containing tracts $(N=43)$ were not statistically different from those 597 populated tracts in Queens not containing portions of NCS segments; variability in most indicators was comparable in tracts containing and not containing segments.

Conclusions: In a diverse urban setting, the NCS segment selection process succeeded in identifying recruitment areas that are, as a whole, representative of Queens County, for a broad range of community-level variables.

Keywords: Neighborhood health, Social environment, Built environment, Children, Study design

\section{Background}

The National Children's Study (NCS) is a prospective cohort study designed to identify preventable causes of childhood disease in the United States, with the full cohort to include 100,000 children enrolled from 105 counties (or groups of counties) across the country. A major premise of the NCS is that findings could be extrapolated to represent the American experience, and inform public

\footnotetext{
* Correspondence: Agr3@columbia.edu

'Department of Epidemiology, Mailman School of Public Health, 722 West

168th Street, New York, NY 10032, USA

Full list of author information is available at the end of the article
}

policy [1-4]. Seven "pilot" or Vanguard Centers began recruitment in 2009 and Duplin County, NC and Queens County, NY were the first to enumerate and screen potential subjects residing within predetermined geographic areas, referred to as segments. These segments were selected to produce a representative subsample of the county that would, given estimated recruitment rates, result in recruitment into the study of approximately 1,000 mothers giving birth over a four year period.

The World Health Organization (WHO) has identified neighborhood contextual exposures as a central element

\section{Biomed Central}


in its Multiple Exposures Multiple Effects (MEME) framework for studying childhood health [5]. Multiple neighborhood contextual characteristics have been shown to affect a range of developmental and health outcomes across childhood and adolescence, with cognitive functioning being one of the most widely investigated. The socioeconomic composition of neighborhood residents is associated with cognitive functioning [6-11], and there is some evidence that this effect differs by race and ethnicity $[8,9]$. As is the case with cognitive functioning, school achievement has also been associated with neighborhood socioeconomic status (SES) [12], and gender-specific effects have been shown [13]. In addition to effects on cognitive function, a growing literature demonstrates neighborhood effects on both physical and mental health and behavior. Proximity to and quality of parks, playgrounds, and recreational facilities have been associated with physical activity, health behaviors and body size [14-24]. Similarly, indices of neighborhood walk-ability, such as population density and land use, are associated with physical activity through walking and active travel among youth $[25,26]$. Some studies demonstrate that physical deterioration (e.g. graffiti, litter or abandoned buildings) is associated with lower physical activity, higher rates of overweight in children, and lower parental support for children playing in local playgrounds [27-30]. Other important associations between neighborhood characteristics and physical outcomes include traffic-related respiratory symptoms [31] and injuries [32]. Among the mental health and behavioral outcomes influenced by neighborhood conditions (primarily SES-related), are psychological distress [33], substance use [34], and behavioral problems $[10,35,36]$.

Consistent with the WHO MEME framework, one of the goals of the NCS is to understand how neighborhood environments influence child development and disease risk [1]. However, there are ethical and logistical challenges to the achievement of this goal within the context of a national, multi-site study such as the NCS, which is coordinated by a central data center. Outside of data collected nationally by the Census Bureau through the American Community Survey the availability and quality of geo-spatially aligned data describing neighborhood contexts varies tremendously across cities in the United States. In addition, our experience has been that negotiating licenses with local Governmental agencies for geo-spatial data and the sharing of geospatial data is often facilitated by relationship building, trust, involvement in the community and personal connections, suggesting a substantial role for local research teams in the acquisition of geo-spatial data. It is also common that licenses for such data specify that the data not be further shared with other groups, such as the NCS data center.
One approach to conducting neighborhood health studies within the NCS would be for the central NCS data repository to release to authorized investigators analytical data sets with the residential longitude and latitude of the study subjects so the investigators could create their own neighborhood context variables. This would provide the investigators with the flexibility of creating their own neighborhood definitions (e.g. to use administrative units such as postal codes or radial buffers around the address) for study subjects and of using locally available geo-spatial data to create neighborhood measures, but could compromise the confidentiality of the study subjects. Alternatively the data center could centrally perform geo-processing functions as requested by NCS investigators and provide analytical data sets that include neighborhood context variables but not residential identifiers. For analyses using unique or not universally available geo-spatial data sources, the logistics of the NCS data center sourcing and centrally negotiating data license agreements could be a serious barrier to research. Thus, strategies to protect subject confidentiality, efficiently acquire geo-spatial data and adhere to data licensing agreements will be needed to support analyses of neighborhood health effects. Other large scale national studies in the United States have taken a variety of approaches to these issues, and we suggest that a working group of interested parties be formed to study how neighborhood effect studies can best be conducted within the NCS.

From an international perspective efforts to establish procedures for the conduct of neighborhood effects research within the NCS should be cognizant of international efforts to coordinate the conduct of new large scale birth-cohort studies [37]. The World Health Organization (WHO) is currently working to strengthen, international cooperation in the conduct of birth cohort studies, with a focus on harmonizing disease outcome, biomarker and exposure measures so that study data may be pooled [37]. Under WHO's MEME framework, the measurement of community contextual exposures is one of the "four ingredients required for the monitoring of children's environmental health" [38]. The development of compatible methods to define and measure neighborhood contexts across birth cohort studies and cross-cultural research to identify contextual constructs that are salient across cultures and regions are areas that warrant consideration within WHO birth cohort coordination activities.

Early work from Queens has described extant data sources at the national, county and local level that can be used to estimate chemical exposures for the children enrolled in the NCS [39]. Following the WHO MEME framework, we here broaden the discussion of neighborhood environment to include the social and built 
environment of the Queens Vanguard site recruitment segments and Queens as a whole [1,40]. Our goal here is to identify multiple domains of neighborhood context and key variables describing the dimensions of these domains. Important considerations for conducting neighborhood health studies are whether the neighborhoods are representative of the larger area to which study results will be generalized, and whether there is sufficient variability across neighborhoods for comparisons of contextual variables to be meaningful. Consideration and analysis of these issues for neighborhood effects studies should be part of the WHO efforts to coordinate and harmonize new birth cohort studies within the MEME framework [37,38]. Here we compare the Queens segment areas to the whole of Queens to determine if the segments are representative of Queens County on the selected indicator variables and assess the extent to which the segments vary in neighborhood conditions.

\section{Methods}

Based on the literature researchers with the Columbia University Built Environment and Health Research Group (BEH), the Columbia Children's Center for Environmental Health and the NCS Queens Vanguard site identified nine major domains of social and built environment contexts of interest. The domains of interest and key indicator variables are described in Table 1. Available geo-spatial data from the Census and other sources have been gathered by $\mathrm{BEH}$, and subsequently cleaned and geo-processed for use with the Queens Vanguard segments. Some of the data sources are available nationally, while others are unique to NYC (see Table 1).

The overall strategy for segment selection in the NCS has been reported previously elsewhere [41]. The Queens Vanguard Center comprises 18 geographic areas, referred to as segments, which are noncontiguous, relatively homogeneous areas from which study subjects are recruited. Historical birth counts from the New York City (NYC) and New York State (NYS) Vital Statistics Registries (2000-2004) at the census tract level and NYC Housing Department data were used to predict births within census blocks. Census blocks were chosen to be representative in terms of race/ethnicity, poverty status, age distribution and foreign born status of women of child bearing age. These blocks were then combined to achieve eighteen segments that would produce 250 live births per year. The eighteen segments were selected in a two-phase stratified sampling approach that attempted to equalize the probability of selection of segments with diverse sociodemographic and other characteristics. The segment boundaries were guided by boundaries of historical neighborhoods as catalogued by the NYC Department of City Planning, and examination of proposed segment maps to ensure that selected boundaries did not cross major roadways, parks or other entities around which communities are formed. Between March-August, 2008 all dwelling units (DU) within the segments were identified $(\mathrm{N}=11,116)$ and to date, 44 newly constructed DUs have been included in the sample, resulting in a total of 11,160 households [2].

Summary statistics were generated for these neighborhood context variables. Queens NCS segments were then compared to the remainder of Queens County to determine the degree to which segment selection (based on relatively few birth and demographic variables) yielded areas that were representative of Queens as a whole. Mean, median, quartile and minimum and maximum values were calculated for each variable; and segmented and non-segmented areas were compared using $\mathrm{t}$-tests and non-parametric tests.

To preserve the confidentiality of the study subjects during the recruitment phase of the NCS, the locations of the Queens segments are not disclosed. Thus summary statistics for Census tracts that include Census blocks that are part of the segments were calculated and compared to summary statistics for Census tracts that do not include segment Census blocks (see Figures 1 and 2). To ensure the stability of summary statistics calculated at the tract level, tracts containing a total population less than 500 were excluded from analysis $(n=$ 75); one additional tract that consisted predominantly of institutionalized individuals unlikely to include children, and this tract was also excluded from analysis. The remaining 640 tracts included in the analysis contained a total population of $2,225,761$, or $99.9 \%$ of the population of Queens. A total of 43 tracts with a population of 168,503 contained NCS segments; a total of 597 tracts with a population of 2,057,258 included the remaining Queens tracts that did not contain NCS segments. Analyses in this paper did not use human subject data.

\section{Results}

Descriptive statistics comparing Census tracts containing portions of NCS segments $(\mathrm{N}=43)$ with those tracts not containing portions of the NCS segments $(\mathrm{N}=597)$ are shown in Table 2 . To preserve anonymity of the segments only means and inter-quartile ranges are reported in Table 2. Across the nine domains characterizing Queens communities, the NCS segment-containing tracts were, as a group quite similar to the tracts in Queens not containing portions of NCS segments. More specifically, of the 53 community indicators representing these nine domains, a statistically significant difference $(\mathrm{p}<0.05)$ was found for only 7 indicators, using either a non-parametric (Mann-Whitney $\mathrm{U}$ ) or a parametric ( $\mathrm{t}$ test) statistical test. The indicators with statistically significant differences were as follows: NCS segment- 


\section{a. Demographic Variables}

1). Total population

2). Population density (10k people / $\mathrm{km}^{2}$ )

3). Total number of house holds

4). Proportion below age 18

5). Proportion above age 64

6). Proportion Female

7). Race
a). Proportion White only
b). Proportion Black only
c). Proportion Asian-Pacific Islander only
d). Proportion other only
e). Proportion two or more races listed

8). Ethnicity
a). Proportion Hispanic
b). Proportion foreign born
c). Proportion linguistically isolated

\section{b. Socio-economic Variables}

1). Proportion with High school degree or beyond

2). Proportion with a Bachelors degree or beyond

3). Per capita income

4). Median house hold income

5). Proportion of people whose income is below the federal poverty level

6). Unemployment rate

\section{c. Information about Households}

1). Average house hold size

2). Total housing units

3). Percent of households renting their home

\section{d. Maternal Birth Statistics}

1). Proportion of births to women $<17$ years old

2). Proportion of births to women with less than 12 years of education

3). Proportion of births to primiparous mothers

4). Proportion of mothers with late or no prenatal care

5). Proportion of births to mothers receiving Medicaid

6). Proportion of births that are low birth weight

7). Proportion of births that are pre-term.

\section{e. Transit Related Variables}

1). Proportion of commuters using private cars

2). Proportion of commuters using public transit

3). Subway stop density (stops $/ \mathrm{km}^{2}$ )
US Census 2000 SF3 file

US Census 2000 SF3 file

US Census 2000 SF3 file

US Census 2000 SF3 file

US Census 2000 SF3 file

US Census 2000 SF3 file

US Census 2000 SF3 file

US Census 2000 SF3 file

US Census 2000 SF3 file

US Census 2000 SF3 file

US Census 2000 SF3 file

US Census 2000 SF3 file

US Census 2000 SF3 file

US Census 2000 SF3 file

US Census 2000 SF3 file

US Census 2000 SF3 file

US Census 2000 SF3 file

US Census 2000 SF3 file

US Census 2000 SF3 file

US Census 2000 SF3 file

US Census 2000 SF3 file

US Census 2000 SF3 file

US Census 2000 SF3 file

US Census 2000 SF3 file

US Census 2000 SF3 file

New York City Department of Health and Mental Hygiene, Office of Vital Statistics. New York City Department of Health and Mental Hygiene

New York City Department of Health and Mental Hygiene

New York City Department of Health and Mental Hygiene

New York City Department of Health and Mental Hygiene

New York City Department of Health and Mental Hygiene

New York City Department of Health and Mental Hygiene

US Census 2000 SF3 file

US Census 2000 SF3 file

NYC Metropolitan Transit Authority 


\section{Table 1 Domains of Neighborhood Characteristics, Key Variables and Data Sources (Continued)}
4). Bus stop density (stops $/ \mathrm{km}^{2}$ )
5). Street network distance to central business district $1(\mathrm{~km})$
6). Street network distance to central business district $2(\mathrm{~km})$
7). Street length weighted average speed limit

\section{f. Greenery and Playgrounds}

1). Street trees per $\mathrm{km}^{2}$

2). Number of playgrounds

\section{g. Safety and Social Disorder}

1). Pedestrians injured in car accidents

2). Bicyclists injured in car accidents

3). Average crime complaints per capita (2001-2004)

\section{h. Land Use Variables}
1). Proportion of building space that is residential
2). Proportion of building space that is commercial
3). Proportion of lot area zoned commercial
4). Residential-commercial land use mix
5). Number of buildings
6). Average number of floors per building
7). Walk-ability score

\section{i. Pollution Sources}

1). Percentage of Tract within $805 \mathrm{~m}$ of a TRI Site

2). Percentage of Tract within $402 \mathrm{~m}$ of a Stationary Point Source

3). Proportion of tract with 300 meters of a major trucking route

4). Proportion of tract covered by any of the above

\author{
NYC Metropolitan Transit Authority \\ New York State Street Centerlines \\ New York State Street Centerlines \\ New York State Street Centerlines
}

New York City Department of Parks \& Recreation

New York City Department of Parks \& Recreation

New York State Department of Transportation

New York State Department of Transportation

New York City Police Department, CompStat Crime Data.

\begin{abstract}
New York City Department of City Planning, PLUTO database
New York City Department of City Planning, PLUTO database

New York City Department of City Planning, PLUTO database

New York City Department of City Planning, PLUTO database

New York City Department of City Planning, PLUTO database

New York City Department of City Planning, PLUTO database
\end{abstract}

A composite score including population density, intersection density, subway and bus stop density and residential-commercial land use mix.

EPA, Toxic Release Inventory Database

EPA, National Emissions Inventory

NYC Metropolitan Transit Authority containing tracts had a higher proportion of the Asian and Pacific Islanders, a smaller proportion of individuals reporting that they were members of two or more races, a lower proportion of female residents, a smaller proportion of teen mothers, a smaller percentage of low-birth weight births, fewer bicyclists injured in car accidents, and a lower proportion of Tract area within a $1 / 4$ mile of a pollution point source.

Because of the relatively large number of tests involved in these comparisons, many of the seven statistically significant differences are probably not 'significant' in the sense that they indicate that segment tracts are not 'representative' of non-segment tracts. No adjustment was made for multiple comparisons; given the fact that 53 tests of each type were performed, it would be expected that approximately 3 indicators would be significantly different at the 0.05 level for each type of test-a total of seven significant differences-purely by chance.

Variability in measures among tracts is arguably as important as central tendency with respect to 'representativeness'. If the tracts containing NCS segments were systematically less variable than the tracts not containing segments with respect to the community context indicators, the NCS segments could not be considered representative of Queens as a whole, even if the mean level of the indicators was comparable. However, an examination of the ratio of inter-quartile ranges (IQR ratio) for the two groups suggests that the two sets of tracts are in general comparable in terms of variability: as can be seen in Table 2, 25 indicators had an IQR ratio within $20 \%$ of 1 (equal variability); an additional 23 had an IQR ratio no more than 1.5 and no less than 0.5 , only 4 indicators had a ratio of $<0.5$ or greater than 1.5 (two indicators had inter-quartile ranges of zero, so that the IQR could not be calculated).

To provide a sense of the geographic variability of these indicators, two maps are provided, one showing the distribution of percent low birth weight $(<2500 \mathrm{~g})$ in Queens Census tracts (Figure 1), the other showing the distribution of percent foreign born individuals. The maps also show the approximate size of an average 


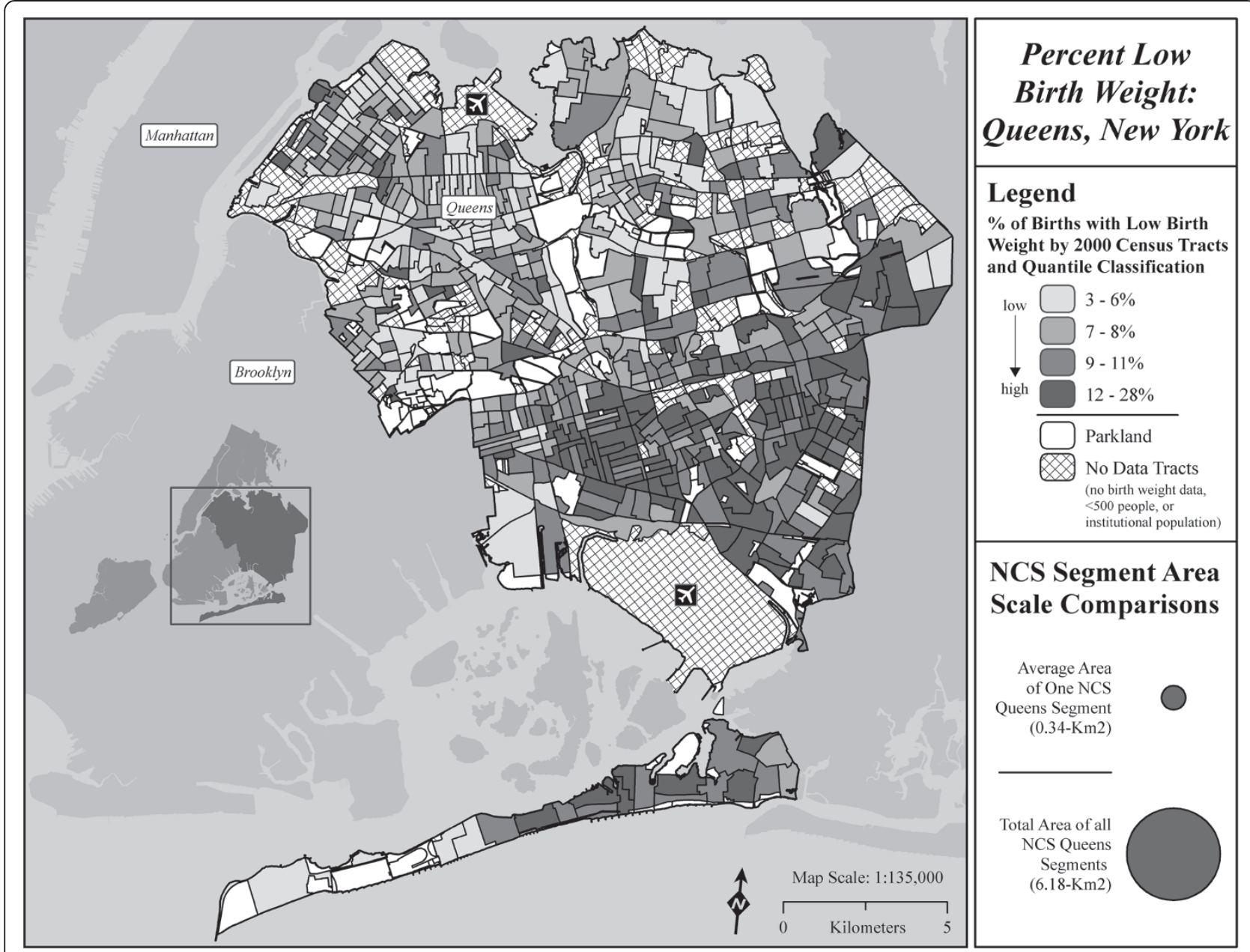

Figure 1 Distribution of percent low birth weight $(<\mathbf{2 5 0 0} \mathbf{~ g})$ in Queens Census tracts. In comparison to the area of Queens $\left(281.59 \mathrm{~km}^{2}\right)$ shown on the map, the circles in the legend of the maps represent the total area of the 18 segments (middle circle $-6.18 \mathrm{~km}^{2}$ ) and the average area of a Queens NCS segment (smallest circle $-0.34 \mathrm{~km}^{2}$ ).

segment in relation to Queens as a whole, and the approximate size of all 18 segments combined.

\section{Discussion}

Previous smaller, longitudinal birth cohorts, both in the US and internationally, have made enormous contributions to our understanding of how maternal nutrition, environmental exposures and social circumstances shape child health and development [42-47]. The NCS is designed to expand upon this prior work, at a scale that will allow for analyses of interactions between environmental pollutants, genetics, neighborhood effects and social forces [1]. This scale will facilitate the identification of determinants of childhood disease and the characterization of susceptible sub-populations of children that require a higher level of protection or interventions. Applying the WHO MEME framework to the NCS, we described several domains of neighborhood context variables that may be important determinants of child health and development. While not exhaustive, these domains represent areas of concern identified in the literature, including our own studies of neighborhood effects on health. The variables highlighted here as measures of these domains do not represent the full breadth of dimensions for these domains, but they do represent the key element, and were selected because of the availability of geo-spatial data sets with sufficient spatial resolution in the data to characterize Census tracts.

The analyses presented here document that at the tract level, the Queens NCS segments are representative of Queens overall for a large number of neighborhood level variables. The few differences identified are compatible with chance associations arising across a large number of comparisons, and there are no readily apparent processes to causally explain the differences. The block groups comprising the NCS segments were selected based on a relatively small number of socio- 


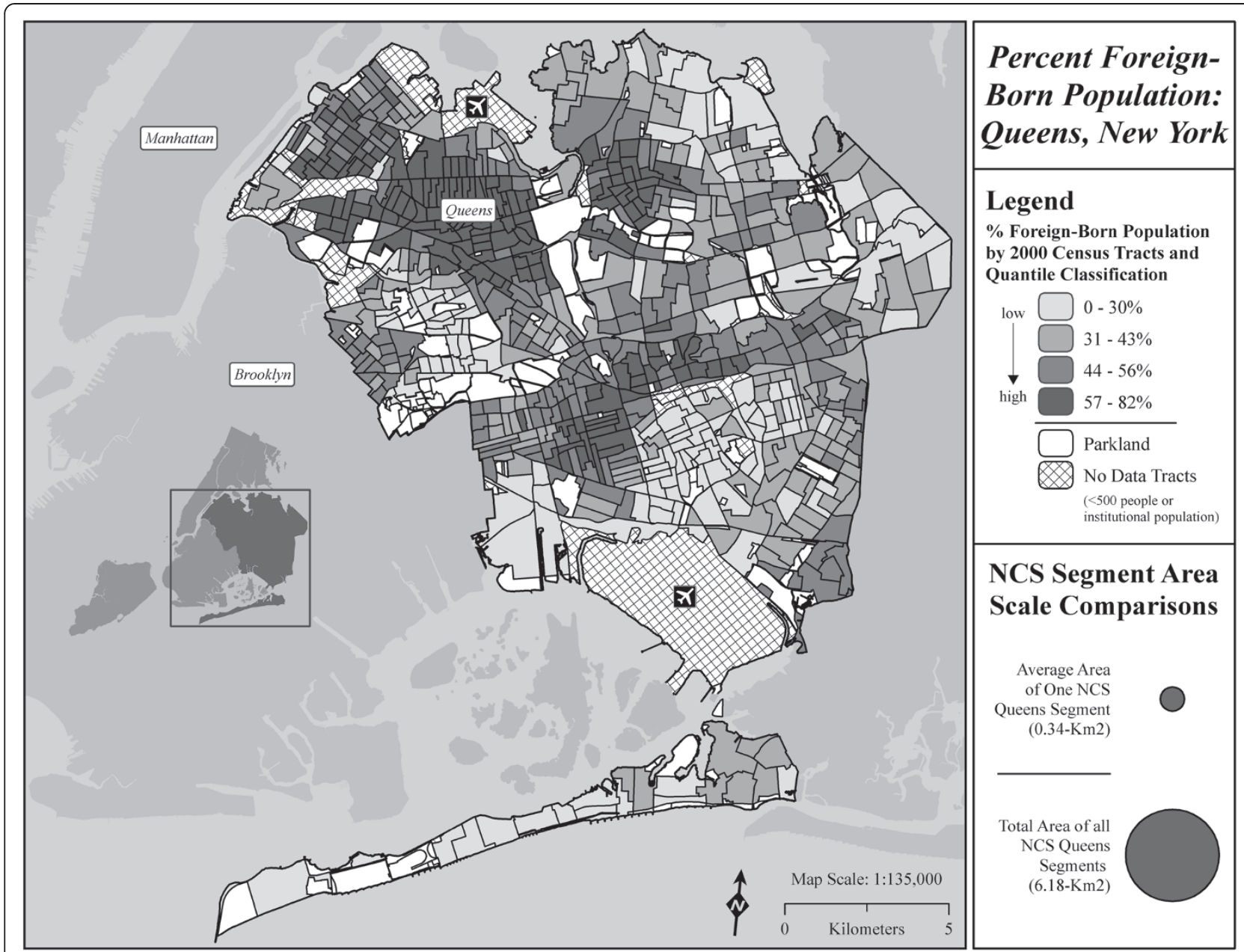

Figure 2 Distribution of percent foreign-born population in Queens Census tracts. In comparison to the area of Queens (281.59 $\left.\mathrm{km}^{2}\right)$ shown on the map, the circles in the legend of the maps represent the total area of the 18 segments (middle circle $-6.18 \mathrm{~km}^{2}$ ) and the average area of a Queens NCS segment (smallest circle $-0.34 \mathrm{~km}^{2}$ ).

demographic and vital statistics. However, these variables appear to be correlated with a larger number of other socio-demographic and urban design variables, such that the tracts including portions of the NCS segments are very similar to tracts not including portions of the NCS segments. In addition, these analyses suggest that the Queens segments include a substantial amount of variation in neighborhood context variables for many domains of interest in neighborhood health studies.

Census tracts in NYC are sufficiently small that they are likely to be representative of the segments, but in recognition of disclosure risks, are sufficiently large that tabulated summary statistics won't reveal the location of the segments. Furthermore, since women and children living in the segments are likely to experience social and environmental conditions in area adjacent to the segments, the use of Census tracts encompassing the segments partially accounts for this spatial spillover effect [48]. The analyses show that results of neighborhood context studies derived from the Queens site will likely be generalizable to Queens as a whole.

Measures of many social and economic constructs can be developed from national American Community Survey and Economic Census data and used across NCS sites, leveraging the substantial between-site variation in neighborhood contexts. In addition, other geo-spatial data-sets are often available at the municipal or county level, providing each NCS site with unique spatial data and opportunities to perform neighborhood context analyses. Geo-spatial data sets developed by NYC agencies have been extremely useful in studies of adult health in NYC [49-53] and provide unique opportunities for studying the effects of neighborhood built and social environments on child health and development $[49,54]$.

The issue of differences in availability and quality of neighborhood contextual data across regions is amplified when one considers WHO's efforts to harmonize and coordinate birth cohort studies internationally. Part of 
Table 2 Comparison of Queens Census Tracts without Segments $(n=597)$ and With NCS Segments ( $=43)$ : Mean, InterQuartile Range(IQR), and IQR Ratio ${ }^{1}$

\begin{tabular}{|c|c|c|c|c|c|}
\hline \multirow[b]{2}{*}{ a. Demographic Characteristics } & \multicolumn{2}{|c|}{ Without Segments } & \multicolumn{2}{|c|}{ With Segments } & \multirow[b]{2}{*}{ IQR Ratio ${ }^{2}$} \\
\hline & Mean & IQR & Mean & IQR & \\
\hline 1) Total population & 3446 & 2493 & 3919 & 3313 & 1.33 \\
\hline 2) Population Density & 1.36 & 1.06 & 1.54 & 0.73 & 0.69 \\
\hline 3) Number of Households & 1212 & 870 & 1350 & 1252 & 1.44 \\
\hline 4) $\%$ Population $<18$ & 24 & 8 & 24 & 7 & 0.88 \\
\hline 5) \% Population $>64$ & 13 & 7 & 12 & 3 & 0.43 \\
\hline 6) $\%$ Female* & 52 & 4 & 51 & 3 & 0.75 \\
\hline 7) Race & & & & 3313 & \\
\hline a) $\%$ White only & 43 & 48 & 40 & 32 & 0.67 \\
\hline b) \% Black only & 24 & 35 & 22 & 24 & 0.69 \\
\hline c)\% Asian-Pacific Islander only** & 16 & 21 & 22 & 25 & 1.19 \\
\hline d) $\%$ other only & 11 & 15 & 11 & 11 & 0.73 \\
\hline e) $\%$ two or more races listed** & 6 & 5 & 5 & 4 & 0.80 \\
\hline \multicolumn{6}{|l|}{ 8) Ethnicity } \\
\hline a) \% Hispanic & 22 & 23 & 22 & 17 & 0.74 \\
\hline b) $\%$ foreign born & 43 & 25 & 46 & 28 & 1.12 \\
\hline c) \% linguistically isolated & 15 & 16 & 17 & 21 & 1.31 \\
\hline \multicolumn{6}{|l|}{ b. Socio-economics } \\
\hline 1) $\%$ with at least a High School degree & 74 & 14 & 75 & 11 & 0.79 \\
\hline 2) $\%$ with Bachelor's degree or higher & 23 & 15 & 24 & 12 & 0.8 \\
\hline 3) Per Capita Income & 19675 & 7885 & 19155 & 5581 & 0.71 \\
\hline 4) Median Household Income & 46011 & 16603 & 45261 & 16798 & 1.01 \\
\hline 5) \% Below Poverty Level & 14 & 11 & 14 & 10 & 0.91 \\
\hline 6) Unemployment Rate & 8 & 5 & 7 & 5 & 1.00 \\
\hline \multicolumn{6}{|l|}{ c. Households } \\
\hline 1) Average Household Size & 2.94 & 0.7 & 2.9 & 0.58 & 0.83 \\
\hline 2) Total Housing Units & 1265 & 891 & 1412 & 1290 & 1.45 \\
\hline 3)\% Households Renting & 51 & 40 & 56 & 45 & 1.13 \\
\hline \multicolumn{6}{|l|}{ d. Birth-Related:\% of Births... } \\
\hline 1) to Women $<17^{*}$ & 2 & 2 & 2 & 2 & 1.00 \\
\hline 2) to Women with $<12$ Years Education. & 20 & 14 & 18 & 12 & .86 \\
\hline 3) to Primiparous Women & 35 & 8 & 36 & 8 & 1.00 \\
\hline 4) to Women with little or no prenatal care & 9 & 6 & 9 & 5 & 0.83 \\
\hline 5) to Women on Medicaid & 50 & 22 & 55 & 22 & 1.00 \\
\hline 6) Low Birth Weight** & 9 & 5 & 8 & 2 & 0.40 \\
\hline 7) Pre-Term & 13 & 5 & 12 & 6 & 1.2 \\
\hline \multicolumn{6}{|l|}{ e. Transit Related } \\
\hline 1) \% Commuters Using Cars & 47 & 24 & 45 & 23 & 0.96 \\
\hline 2) \% Commuters Using Public Transport & 45 & 21 & 46 & 19 & 0.90 \\
\hline 3) Subway Stop Density & 0.49 & 0 & 0.32 & 0 & - \\
\hline 4) Bus Stop Density & 27 & 20 & 25 & 26 & 1.30 \\
\hline 5) Distance to central business district $1(\mathrm{~km})$ & 11 & 5 & 11 & 6 & 1.20 \\
\hline 6) Distance to central business district $2(\mathrm{~km})$ & 10 & 6 & 10 & 8 & 1.33 \\
\hline 7) Street length weighted average speed limit & 27 & 3 & 27 & 3 & 1.00 \\
\hline
\end{tabular}


Table 2 Comparison of Queens Census Tracts without Segments $(n=597)$ and With NCS Segments ( $=43)$ : Mean, InterQuartile Range(IQR), and IQR Ratio' ${ }^{1}$ (Continued)

\begin{tabular}{|c|c|c|c|c|c|}
\hline \multicolumn{6}{|l|}{ f. Playground and Greenery } \\
\hline 1) Street Trees per $\mathrm{km}^{2}$ & 1100 & 752 & 1040 & 491 & 0.65 \\
\hline 2) Number of Playgrounds & 0.36 & 1 & 0.44 & 1 & 1.00 \\
\hline \multicolumn{6}{|l|}{ g. Safety and Social Disorder } \\
\hline 1) Pedestrians Injured in Car Accidents & 3 & 4 & 3 & 5 & 1.25 \\
\hline 2) Bicyclists Injured in Car Accidents*, 3 & 0.71 & 1 & 1.19 & 2 & 2.00 \\
\hline 3) Annual Crime Complaints per capita & 0.016 & 0.004 & 0.016 & 0.005 & 1.25 \\
\hline \multicolumn{6}{|l|}{ h. Land Use } \\
\hline 1) \% of Building Space - Residential & 87 & 12 & 84 & 13 & 1.08 \\
\hline 2) $\%$ of Building Space - Commercial & 13 & 12 & 16 & 13 & 1.08 \\
\hline 3) \% Lot Area Zoned Commercial & 12 & 14 & 11 & 14 & 1.00 \\
\hline 4) Land Use Mix & 34 & 35 & 29 & 30 & .85 \\
\hline 5) Number of Buildings & 513 & 298 & 489 & 232 & 0.78 \\
\hline 6) Mean Floors Per Building & 2.2 & 0.4 & 2.5 & 0.2 & 0.50 \\
\hline 7) Walk-ability & -1 & 4 & -1 & 3 & 0.75 \\
\hline \multicolumn{6}{|l|}{ i. Pollution Sources } \\
\hline 1)\% of Tract within $805 \mathrm{~m}$ of a TRI Site & 29 & 67 & 31 & 69 & 1.03 \\
\hline 2) $\%$ of Tract within $402 m$ of Point Source & 4 & 0 & 1 & 0 & - \\
\hline 3) $\%$ of tract with $300 \mathrm{~m}$ of truck route & 39 & 40 & 37 & 51 & 1.28 \\
\hline 4) $\%$ of tract covered by any of the above & 54 & 67 & 53 & 55 & 0.82 \\
\hline
\end{tabular}

the efforts to standardize measures of exposure should include the identification of neighborhood/community level contextual variables that can be used across studies. This would necessitate the development of cross-cultural knowledge on how commonly used neighborhood constructs like neighborhood disorder and neighborhoodlevel socioeconomic conditions translate across nations. In addition, since much of the work on neighborhood contextual effects on health has been conducted in the United States and Western Europe, work on identifying additional neighborhood contextual constructs salient to other nations/regions is vital. Similarly, cross-cultural research on how the concepts of "neighborhood-level" or "community-level" are defined or are salient needs to be undertaken $[40,48,55,56]$. Current literature on neighborhood effects commonly uses administrative boundaries (e.g. postal codes or Census tracts) or radial or street network buffers centered on a subject's home to define neighborhoods $[48,51,55]$. However, just as within a single region individual's conceptualizations of neighborhood can vary, there are likely to be substantial differences in how individuals define neighborhoods across international contexts [57-59]. Furthermore, while the definition of a neighborhood used in research should represent the geographic scale over which a neighborhood level phenomena is thought to causally influence health, the geographic scale across which social and physical contexts affect health may vary across cultures.

\section{Conclusions}

The WHO MEME framework identifies neighborhood and community contexts as one of the four key indicators of children's environmental health [38]. In applying the MEME framework to the NCS, we have identified multiple domains of neighborhood context and key variables describing the dimensions of these domains that can be used in the National Children's Study (NCS) site in Queens and many of which can be used throughout the NCS. We show that the selection of block groups to form the NCS segments in Queens using a short list of neighborhood contextual indicators (race/ethnicity, poverty status, age distribution and foreign born status of women of child bearing age) produced segments that are representative of Queens County, across many neighborhood variables. The segments also show a substantial amount of variation in neighborhood contextual variables for several 
domains of interest for neighborhood health studies. This suggests that unbiased studies of contextual and individual level risk factor effects on child health outcomes can be conducted within the Queens site. From a larger perspective, the NCS presents a valuable opportunity for conducting studies of the role of neighborhood context on child development and health. The development of strategies to conduct neighborhood health research and protect subject confidentiality, efficiently acquire geospatial data and adhere to data licensing agreements should be a priority. These issues plus the development of an understanding of the content validity of neighborhood contextual measures and the very meaning of "neighborhood" across cultures and regions should be a priority for $\mathrm{WHO}$ efforts to coordinate and harmonize data across birth cohorts [37].

\section{Abbreviations}

NCS: National Children's Study; SES: Socioeconomic status; NYC: New York City; NYS: New York State; DU: Dwelling unit; IQR: Inter-quartile range; WHO: World Health Organization.

\section{Competing interests}

The authors are investigators and collaborators of the Queens, New York Vanguard Center of the National Children's Study, and the Columbia Center for Children's Environmental Health. The NCS has been funded in whole or in part with Federal funds from the National Institute of Child Health and Human Development, National Institutes of Health, under Contracts Number NICHD HHSN275200503411C/N01-HD-5-3411. The Columbia Center for Children's Environmental Health has been supported by the National Institute of Environmental Health Sciences (5P01ES009600, 5R01ES008977, 5R01ES11158, 5R01ES012468, 5R01ES10165), and United States Environmental Protection Agency (R827027, 82860901, RD-832141). The content of this publication does not necessarily reflect the views or policies of the Department of Health and Human Services, nor does mention of trade names, commercial products, or organizations imply endorsement by the U.S. Government.

\section{Author details}

'Department of Epidemiology, Mailman School of Public Health, 722 West 168th Street, New York, NY 10032, USA. ${ }^{2}$ Heilbrunn Center for Population \& Family Health, 60 Haven Ave B-3, New York, NY 10032, USA. Institute for Social and Economic Research and Policy, 420 West 118th Street, New York, NY 10027, USA. ${ }^{4}$ Departments of Pediatrics and Environmental Medicine, NYU School of Medicine and NYU Wagner School of Public Service, ${ }^{5}$ Department of Biostatistics, Mailman School of Public Health, 722 West 168th Street, New York, NY 10032, USA.

\section{Authors' contributions}

AR conducted the statistical analyses and wrote the paper. VAR helped interpret the data and edit the manuscript. JQ generated the geospatial measures describing Census tract characteristics. GL helped conceptualize the geospatial measures of interest and frame the Discussion section. LT provided editorial feedback on the paper and jointly directs the Queens site of the NCS. ES helped interpret the data and contributed to the writing of the manuscript. HFA managed the Queens site data, conceptualized the research project, conducted part of the statistical analyses, and helped draft the manuscript. All authors read and approved the final manuscript.

Received: 6 December 2011 Accepted: 5 June 2012

Published: 5 June 2012

\section{References}

1. Landrigan PJ, Trasande L, Thorpe LE, Gwynn C, Lioy PJ, D'Alton ME, Lipkind HS, Swanson J, Wadhwa PD, Clark EB, et al: The National Children's Study: a 21-year prospective study of 100,000 American children. Pediatrics 2006, 118(5):2173-2186.
2. Trasande L, Andrews H, Goranson C, Li W, Barrow E, Vanderbeek S, McCrary B, Allen S, Gallagher K, Rundle A, et al: Early experiences and predictors of recruitment success for the National CHildren's Study. Pediatrics 2011, 127(2):261-268.

3. Trasande L, Cronk CE, Leuthner SR, Hewitt JB, Durkin MS, McElroy JA, Anderson HA, Landrigan PJ: The National Children's Study and the children of Wisconsin. WMJ 2006, 105(2):50-54.

4. Trasande L, Landrigan PJ: The National Children's Study: a critical national investment. Environ Health Perspect 2004, 112(14):A789-A790.

5. Briggs D: Making a difference: indicators to improve children's environmental health. In Indicators. Geneva: WHO; 2003.

6. Mayer S, Jencks C: Growing up in poor neighborhoods: how much does it matter? Science 1989, 243(4897):1441-1445.

7. Breslau N, Chilcoat H, Susser E, Matte T, Liang K, Peterson E: Stability and change in children's intelligence quotient scores: a comparison of two socioeconomically disparate communities. Am J Epidemio/ 2001, 154(8):711-717.

8. Brooks-Gunn J, Duncan G, Klebanov P, Sealand N: Do neighborhoods influence child and adolescent development? Am J Socio/ 1993, 99:353-395.

9. Duncan G, Brooks-Gunn J, Klebanov P: Economic deprivation and early childhood development. Child Dev 1994, 65(2):296-318.

10. Chase-Lansdale P, Gordon R, Brooks-Gunn J, Klebanov P: Neighborhood and family influences on the intellectual and behavioral competence of preschool and early school-age children. In Neighborhood Poverty: Vol I Context and Consequences for Children. Edited by Brooks-Gunn J, Duncan G, Alber J. New York: Russell Sage Foundation; 1997:79-118.

11. Chase-Lansdale P, Gordon R: Economic hardship and the development of five- and six-year-olds: neighborhood and regional perspectives. Child Dev 1996, 67:3338-3367.

12. Leventhal T, Brooks-Gunn J: The neighborhoods they live in: the effects of neighborhood residence on child and adolescent outcomes. Psychol Bull 2000, 126(2):309-337.

13. Entwisle $D$, Alexander $K$, Olson $L$ : The gender gap in math: its possible origins in neighborhood effects. Am Sociol Rev 1994, 59:822-838.

14. Farley TA, Meriwether RA, Baker ET, Watkins LT, Johnson CC, Webber LS: Safe play spaces to promote physical activity in inner-city children: results from a pilot study of an environmental intervention. Am J Public Health 2007, 97(9):1625-1631.

15. Roemmich JN, Epstein LH, Raja S, Yin L, Robinson J, Winiewicz D: Association of access to parks and recreational facilities with the physical activity of young children. Prev Med 2006, 43(6):437-441.

16. Norman GJ, Nutter SK, Ryan S: Community design and access to recreational facilities as correlates of adolescent physical activity and body-mass index. J Phys Act Health 2006, 3(1 Suppl):S118-S128.

17. Gordon-Larsen P, Nelson MC, Page P, Popkin BM: Inequality in the built environment underlies key health disparities in physical activity and obesity. Pediatrics 2006, 117(2):417-424.

18. Pate RR, Colabianchi N, Porter D, Almeida MJ, Lobelo F, Dowda M: Physical activity and neighborhood resources in high school girls. Am J Prev Med 2008, 34(5):413-419.

19. Frank L, Kerr J, Chapman JS, James: Urban Form Relationships With Walk Trip Frequency and Distance Among Youth. Am J Health Promot 2007, 21(4 suppl):305.

20. Cohen DA, Ashwood JS, Scott MM, Overton A, Evenson KR, Staten LK, Porter D, McKenzie TL, Catellier D: Public parks and physical activity among adolescent girls. Pediatrics 2006, 118(5):e1381-e1389.

21. Sallis JF, Nader PR, Broyles SL, Berry CC: Correlates of physical activity at home in Mexican-American and Anglo-American preschool children. Health Psychol 1993, 12(5):390-398.

22. Timperio A, Crawford D, Telford A, Salmon J: Perceptions about the local neighborhood and walking and cycling among children. Am J Prev Med 2004, 38(1):39-47.

23. Evenson KR, Scott MM, Cohen DA, Voorhees CC: Girls' perception of neighborhood factors on physical activity, sedentary behavior, and BMI [ast]. Obesity 2007, 15(2):430-445.

24. Romero AJ: Low-income neighborhood barriers and resources for adolescents' physical activity. J Adolesc Health 2005, 36:253-259.

25. Kerr J, Rosenberg D, Sallis JF, Saelens BE, Frank LD, Conway TL: Active commuting to school: associations with environment and parental concerns. Med Sci Sports Exercise 2006, 38(4):787-794.

26. Kerr J, Frank L, Sallis JF, Chapman J: Urban form correlates of pedestrian travel in youth: differences by gender, race-ethnicity and household attributes. Transp Res Part D: Transp Environ 2007, 12(3):177-182. 
27. Molnar BE, Gortmaker SL, Bull FC, Buka SL: Unsafe to Play? Neighborhood disorder and lack of safety predict reduced physical activity among urban children and adolescents. Am J Prev Med 2004, 18(5):378-386.

28. Miles R: Neighborhood disorder, perceived safety, and readiness to encourage use of local playgrounds. Am J Prev Med 2008, 34(4):275-281.

29. Lumeng JC, Appugliese D, Cabral HJ, Bradley RH, Zuckerman B: Neighborhood safety and overweight status in children. Arch Pediatr Adolesc Med 2006, 160(1):25-31.

30. Hume C, Salmon J, Ball K: Associations of children's perceived neighborhood environments with walking and physical activity. Am J Health Promot 2007, 21(3):201-207.

31. Dales R, Wheeler A, Mahmud M, Frescura A, Liu L: The influence of neighborhood roadways on respiratory symptoms among elementary schoolchildren. J Occup Environ Med 2009, 51:654-660

32. Macpherson A, Roberts I, Pless IB: Children's exposure to traffic and pedestrian injuries. Am J Public Health 1998, 88:1840-1843.

33. Homel R, Burns A: Environmental quality and the wellbeing of Children. Soc Indic Res 1989, 21:133-158.

34. Ennett $S$, Flewelling $R$, Lindrooth $R$, Norton E: School and neighborhood characteristics associated with school rates of alcohol, cigarette, and marijuana use. J Health Soc Behav 1997, 38:55-71.

35. Sampson R, Groves W: Community structure and crime: testing socialdisorganization theory. Am J Sociol 1989, 94:774-780.

36. Ingoldsby E, Shaw D: Neighborhood contextual factors and the onset and progression of early-starting antisocial pathways. Clin Child Fam Psychol Rev 2002, 5:21-55.

37. Children's environmental health: coordination of new large-scale birth cohort studies. [http://www.who.int/ceh/cohorts/en/].

38. Children's environmental health: Children's environmental health indicators. [http://www.who.int/ceh/indicators/en/]

39. Lioy PJ, Isukapalli SS, Trasande L, Thorpe L, Dellarco M, Weisel C, Georgopoulos PG, Yung C, Brown M, Landrigan PJ: Using national and local extant data to characterize environmental exposures in the national children's study: Queens County, New York. Environ Health Perspect 2009, 117(10):1494-1504.

40. Sampson RJ, Morenoff JD, Gannon-Rowley T: Assessing "neighborhood effects": social processes and new directions in research. Annu Rev Sociol 2002, 28:443-478.

41. Montaquila JM, Brick JM, Curtin LR: Statistical and practical issues in the design of a national probability sample of births for the Vanguard Study of the National Children's Study. Stat Med 2010, 29(13):1368-1376.

42. Rauh VA, Whyatt RM, Garfinkel R, Andrews H, Hoepner L, Reyes A, Diaz D, Camann D, Perera FP: Developmental effects of exposure to environmental tobacco smoke and material hardship among inner-city children. Neurotoxicol Teratol 2004, 26(3):373-385.

43. Rauh VA, Garfinkel R, Perera FP, Andrews HF, Hoepner L, Barr DB, Whitehead $R$, Tang D, Whyatt RW: Impact of prenatal chlorpyrifos exposure on neurodevelopment in the first 3 years of life among inner-city children. Pediatrics 2006, 118(6):e1845-e1859.

44. Perera FP, Rauh V, Whyatt RM, Tsai WY, Tang D, Diaz D, Hoepner L, Barr D, $\mathrm{Tu} Y \mathrm{H}$, Camann D, et al: Effect of prenatal exposure to airborne polycyclic aromatic hydrocarbons on neurodevelopment in the first 3 years of life among inner-city children. Environ Health Perspect 2006, 114(8):1287-1292.

45. Stein AD, Kahn HS, Rundle A, Zybert PA, van der Pal-de Bruin K, Lumey LH: Anthropometric measures in middle age after exposure to famine during gestation: evidence from the Dutch famine. Am J Clin Nutr 2007, 85(3):869-876.

46. Whitaker RC: Predicting preschooler obesity at birth: the role of maternal obesity in early pregnancy. Pediatrics 2004, 114(1):e29-e36.

47. Dubois L, Girard M: Early determinants of overweight at 4.5 years in a population-based longitudinal study. Int J Obes (Lond) 2006, 30(4):610-617.

48. Guo J, Bhat C: Operationalizing the concept of neihborhood: application to residential location choice analysis. J Transportation Geography 2007, 15(1):31-45.

49. Lovasi GS, Quinn JW, Neckerman KM, Perzanowski MS, Rundle A: Children living in areas with more street trees have lower prevalence of asthma. J Epidemiol Community Health 2008, 62(7):647-649.

50. Purciel M, Neckerman KM, Lovasi G, Quinn J, Weiss C, Bader M, Ewing R, Rundle A: Creating and validating GIS measures of urban design for health research. J Environ Psychol 2009, 29(4):457-466.
51. Neckerman KM, Lovasi GS, Davies S, Purciel M, Quinn J, Feder E, Raghunath N, Wasserman B, Rundle A: Disparities in urban neighborhood conditions: evidence from GIS measures and field observation in New York City. J Public Health Policy 2009, 30(Suppl 1):S264-S285.

52. Rundle A, Roux AV, Free LM, Miller D, Neckerman KM, Weiss CC: The urban built environment and obesity in New York City: a multilevel analysis. Am J Health Promot 2007, 21(4 Suppl):326-334.

53. Beard JR, Blaney S, Cerda M, Frye V, Lovasi GS, Ompad D, Rundle A, Vlahov D: Neighborhood characteristics and disability in older adults. J Gerontol B Psychol Sci Soc Sci 2009, 64(2):252-257.

54. Lovasi G, Quinn J, Rauh V, Perera FP, Andrews H, Garfinkel R, Hoepner L, Whyatt RM, Rundle A: Chlorpyrifos exposure and urban residential environment characteristics as determinants of early childhood neurodevelopment. Am J Public Health 2010, E-published ahead of print.

55. Krieger N, Chen JT, Waterman PD, Soobader MJ, Subramanian SV, Carson R: Geocoding and monitoring of US socioeconomic inequalities in mortality and cancer incidence: does the choice of area-based measure and geographic level matter?: the Public Health Disparities Geocoding Project. Am J Epidemiol 2002, 156(5):471-482.

56. Lovasi G, Moudon A, Smith N, Lumley T, Larson E, Sohn D, Siscovick D, Psaty B: Evaluating options for measurement of neighborhood socioeconomic context: evidence from a myocardial infarction case-control study. Health Place 2008, 14(3):453-467.

57. Coulton CJ, Korbin J, Chan T, Su M: Mapping residents' perceptions of neighborhood boundaries: a methodological note. Am J Community Psychol 2001, 29(2):371-383.

58. Lee B, Campbell K: Common ground? Urban neighborhoods as survey respondents see them. Soc Sci Q 1997, 78(4):922-936.

59. Colabianchi N, Dowda M, Pfeiffer KA, Porter DE, Almeida MJ, Pate RR: Towards an understanding of salient neighborhood boundaries: adolescent reports of an easy walking distance and convenient driving distance. Int J Behav Nutr Phys Act 2007, 4:66.

\section{doi:10.1186/1476-072X-11-18}

Cite this article as: Rundle et al:: Use of community-level data in the National Children's Study to establish the representativeness of segment selection in the Queens Vanguard Site. International Journal of Health Geographics 2012 11:18.

\section{Submit your next manuscript to BioMed Central and take full advantage of:}

- Convenient online submission

- Thorough peer review

- No space constraints or color figure charges

- Immediate publication on acceptance

- Inclusion in PubMed, CAS, Scopus and Google Scholar

- Research which is freely available for redistribution 